\title{
Review of Selected Physiotherapeutic Methods Used in the Rehabilitation of Low Back Pain in Light of Evidence-Based Medicine Principles
}

\author{
Aleksander Kaletka ${ }^{1}$ \\ ${ }^{1}$ Institute of Physiotherapy and Health Sciences, Academy of Physical Education in Katowice, Katowice, Poland \\ Correspondence to: Aleksander Kaletka, kaletkaaleksander@gmail.com
}

DOI: https://doi.org/10.5114/for.2021.106944

Received: 19.02.2021 Reviewed: 28.02.2021 Accepted: 01.03.2021

\begin{abstract}
Background: Low back pain (LBP) is a major social and economic problem. Its prevalence in 2015 was 540 million cases, which is 7\% of the general population. A number of physiotherapeutic methods are used to treat these spinal complaints.
\end{abstract}

Aims: This review aimed to compare the effectiveness of the McKenzie Method of Mechanical Diagnosis and Therapy (MDT), Transcutaneous Electrical Nerve Stimulation (TENS), and the Pilates Method Exercise Program (PMEP) in patients with LPB.

Material and methods: This review analyzed studies considered high quality according to the Physiotherapy Evidence Database scale (PEDro score above 7/10) in terms of the effectiveness of the methods analyzed: MDT, TENS, and PMEP.

Results: In the studies reviewed, the MDT method was found to be inconclusively effective, while TENS, considered simple and popular, improved the condition of patients suffering from LBP. The PMEP method was the most effective, although it was compared only with the control group.

Conclusions: It seems necessary to continue randomized clinical trials (RCTs) on these methods with standardized methodology (double and triple blinding, a follow-up evaluation of the participants, selecting therapists with similar professional experience, and a comparison of more methods in high-quality systematic reviews and meta-analyses).
Key words

lower back pain, physiotherapy, evidence-based medicine, PEDro score 


\section{Introduction}

Low back pain (LBP) is a very common problem affecting the entire population, regardless of age. Although its incidence is highest in people of productive age, it is increasingly occurring in much younger people as well $[1,2]$. It is estimated that as many as 540 million people experienced such ailments in 2015, a 54\% increase from 1990 [3].

Its non-specificity causes some difficulty in accurately analyzing the incidence of lumbosacral pain (i.e., there is no identifiable cause for its occurrence). Only a minority of people are diagnosed with specific causes; the most common causes are discopathy of the intervertebral disc, osteoporotic fractures of the vertebrae, significant degenerative changes in the lower spine, inflammatory diseases, tumors, structural deformities, or cauda equina syndrome $[4,5]$.

LBP is the most common cause of disability worldwide [4]. It has a significant impact on the quality of life (QOL) of the affected individuals and their family life and limits their active participation in society. In addition, LBP represents a high cost to health and social care institutions [6] and may require chronic pain medication, which can eventually lead to addiction [7].

Its serious prevalence, its high socio-economic costs, and the fact that LBP is the most frequent cause of disability are the reasons for the call for the development of effective rehabilitation programs supported by evidence-based research.

\section{Aims}

This study compares the effectiveness of three popular physiotherapeutic procedures for the management of LBP: the McKenzie Method of Mechanical Diagnosis and Therapy (MDT), Transcutaneous Electrical Nerve Stimulation (TENS), and the Pilates Method Exercise Program (PMEP).

\section{MDT method}

Garcia et al. [8] conducted a prospective randomized controlled trial (RCT) to evaluate the MDT method compared with a placebo group in pa- tients with LBP. The inclusion criteria included chronic non-specific LBP of at least three months, a pain score of 3 or more measured on the Numeric Pain Rating Scale (NPRS), and an age between 18 and 80 years. The exclusion criteria were contraindications to physical activity, severe pathologies of the spine (i.e., fractures, tumors, infections, severe cardiovascular and metabolic diseases), previous spine surgery, and pregnancy. After prescreening according to the MDT method guidelines, the participants were randomly allocated to one of two groups: MDT $(n=74)$ and placebo $(\mathrm{n}=73)$. The therapy was administered for 5 weeks, twice a week, for 30-40 minutes. A certified MDT method therapist with six years of experience performed the treatments in the MDT group, and the type of activity performed was dependent on the diagnosed dysfunction (postural, dysfunctional, or structural syndrome). The participants in the placebo group were treated with pulsed ultrasound (5 min) and pulsed short-wave diathermy (25 min). The treatments were applied with disconnected cables inside the device. The participants were then clinically evaluated immediately after 5 weeks of therapy and at 3, 6, and 12 months after completing the study. The pain level using NPRS and the degree of disability using the Roland-Morris Disability Questionnaire (RMDQ) were assessed as primary outcomes. The secondary outcomes were the level of kinesiophobia using the Tampa Scale for Kinesiophobia (TSK), global perception of the treatment effect using the Global Perceived Effect (GPE), and functional status using the Patient-Specific Functional Scale (PSFS). The results of the study showed an improvement in pain perception (NPRS) in favor of the MDT group immediately after the experiment: $-1.0(-2.10$ to $-0.01 ; \mathrm{p}=0.04)$ but not in the degree of disability (RMDQ): -0.84 , (-2.62 to 0.93 ; $\mathrm{p}=0.35$ ). No statistically significant differences were observed in the secondary objectives of the study (TSK, GPE, and PSFS) immediately after or during the follow-up assessment.

The aim of the RCT by Halliday et al. [9] was to compare the effectiveness of MDT and motor control exercises (MCEs) in people with chronic 
LBP on trunk muscle thickness and pain levels (Visual Analogue Scale [VAS]), patient functional level (PSFS), and general perception of the therapeutic effect (GPE). The inclusion criteria were LBP of at least three months, identification of a directional preference according to the MDT method, pain located between the 12th rib and the midline of the gluteal cleft, and pain radiating to one or both lower limbs with or without sensory and/or motor dysfunction. Individuals who did not have a directional preference identified in the MDT, those under 18 or over 70 years of age, and those with a history of spinal fractures, previous spinal surgery, or osteoporosis were excluded from the study. Pregnant women were also excluded. Seventy subjects were enrolled in the study and randomly assigned to one of two groups: MDT $(n=35)$ and MCE $(n=35)$. The frequency of the therapy sessions depended on the physiotherapist's assessment; however, it could not exceed 12 visits during the 8 weeks of the study period. The aim of the therapy in the MDT group was to reduce and centralize pain and eliminate pain radiation to the lower limbs. In addition, each participant in the MDT group received a copy of Robin McKenzie's book "Treat your own back" to perform the exercises on their own. The therapy in the MCE group was based on the principles of motor control presented by Hodges et al. [10]. Progression was made after the participants reached successive phases. The exercises were started by learning to activate the deep muscles stabilizing the trunk (i.e., the transversus abdominis and multifidus muscle). Subsequently, they proceeded to perform exercises under dynamic conditions. The participants in the MCE group were instructed to perform a 30-minute exercise session on their own at home. The thickness of the three studied trunk muscles before and after the experiment was determined using ultrasonography (USG). The results of the experiment showed that there was no statistically significant difference between groups in the thickness of the following muscles: transversus abdominis [-5.8\%; 95\% CI: -15.2 to $3.7 ; p=0.23]$, internal oblique $a b-$ dominis [-0.7\%; 95\% CI: -6.6 to $5.2 ; \mathrm{p}=0.82]$, and external oblique abdominis [1.2\%; $95 \%$ CI: -4.3 to $6.8 ; \mathrm{p}=0.65]$. A statistically significant difference was found only in the overall perception of the treatment effect (GPE) [-0.8; 95\% CI: -1.5 to -0.1 ; $\mathrm{p}=0.03]$ in favor of the MDT group. There were no statistically significant differences on the VAS and PSFS.

In their RCT, Murtezani et al. [11] compared the effectiveness of MDT and physical treatments in patients with LBP. The inclusion criteria were chronic non-specific LBP located in the area between the scapulae and the gluteal cleft for at least three months and age between 18 and 65 . The exclusion criteria were ankylosing spondylitis (AS), acute vertebral fractures, scoliosis, spinal surgery three months before the study, severe cardiopulmonary disorders, metabolic diseases, contraindications to electrotherapy, and a lack of informed consent for study participation. The participants who met the above criteria were randomly allocated to one of two groups: MDT (n $=134)$ and electrophysical agents (EPAs) $(n=137)$. Therapy in the MDT group was individually planned by a practitioner experienced in the MDT method and consisted of repetitive mobilizing movements of the lower spine and mobilization performed by the therapist. The number of treatment sessions was limited to 7 during the 4 -week study period, and each session lasted 30-45 minutes. In the EPA group, the therapy included the following treatments: interference currents (IFC) $(3.85 \mathrm{kHz}, 100-130 \mathrm{~Hz})$, continuous ultrasound (CUS) $(1.5 \mathrm{~W} / \mathrm{cm} 2)$ for 5 minutes, and infrared radiation (IR) $(1000 \mathrm{~nm}, 100 \mathrm{~W}, 50 \mathrm{~cm})$ for 15 minutes. The number of treatment sessions was 10 during 4 weeks. The VAS, Oswestry Disability Index (ODI), and finger-to-floor test (FFT) were used to evaluate the effectiveness of the performed therapy. An analysis of the results revealed a higher effectiveness of MDT in terms of pain relief and pain-free range of motion compared with EPAs immediately after the experiment and at the 2- and 3-month follow-ups (Table 1). 
Table 1. Review of studies on the MDT method..

\begin{tabular}{|c|c|c|c|c|c|}
\hline Authors & Procedures & Measures & Results & Limitations & PEDro score \\
\hline $\begin{array}{l}\text { Garcia et al. } \\
2017[8]\end{array}$ & $\begin{array}{l}\text { MDT group } \\
(\mathrm{n}=74) \text { : therapy } \\
\text { carried out twice } \\
\text { a week for } 30- \\
40 \text { min for five } \\
\text { weeks } \\
\text { - placebo group } \\
\text { (n=73); no the- } \\
\text { rapy }\end{array}$ & $\begin{array}{c}\text { NPRS } \\
\text { RMDQ } \\
\text { GPE } \\
\text { TSK } \\
\text { PSFS }\end{array}$ & $\begin{array}{l}\text { - slight and clinically } \\
\text { insignificant differ- } \\
\text {-ence in pain levels } \\
\text { immediately after } \\
\text { therapy in MDT } \\
\text { group } \\
\text { - no statistically sig- } \\
\text {-nificant differen- } \\
\text { ces in the seconda- } \\
\text { ry study outcomes } \\
\text { and at } 3,6 \text {, and } 12 \\
\text { months after the } \\
\text { study completion }\end{array}$ & $\begin{array}{l}\text { - no blinding of the } \\
\text { therapists } \\
\text { - diverse professio- } \\
\text { nal experience of } \\
\text { therapists }\end{array}$ & $8 / 10$ \\
\hline $\begin{array}{l}\text { Halliday et al. } \\
2016[9]\end{array}$ & $\begin{array}{l}\text { MDT group } \\
(\mathrm{n}=35) \text { : the } \\
\text { frequency of } \\
\text { therapy sessions } \\
\text { is specified by } \\
\text { the physiothe- } \\
\text { rapist; no more } \\
\text { than } 12 \text { visits per } \\
8 \text { weeks } \\
\text { - MCE group } \\
\text { (n=35): } 30 \text { minu- } \\
\text { tes of own every- } \\
\text { day exercises }\end{array}$ & $\begin{array}{l}\text { USG } \\
\text { VAS } \\
\text { PSFS } \\
\text { GPE }\end{array}$ & $\begin{array}{l}\text { - no statistically } \\
\text { significant change } \\
\text { between groups } \\
\text { in the thickness } \\
\text { of the examined } \\
\text { muscles (USG) } \\
\text { - statistically signi- } \\
\text { ficant difference in } \\
\text { GPE } \\
\text { - no difference in } \\
\text { VAS and PSF }\end{array}$ & $\begin{array}{l}\text { - no blinding of the } \\
\text { therapist } \\
\text { - small study group } \\
\text { - clinically insigni- } \\
\text { ficant primary } \\
\text { study outcome }\end{array}$ & $7 / 10$ \\
\hline $\begin{array}{l}\text { Murtezani } \\
\text { et al. } 2015[10]\end{array}$ & $\begin{array}{l}\text { MDT group } \\
\text { (n=134): the } \\
\text { frequency of } \\
\text { ther-apy sessions } \\
\text { is speci-fied by } \\
\text { the physio-the- } \\
\text { rapist; no more } \\
\text { than } 7 ; 30-45 \text { min } \\
\text { per } 4 \text { weeks } \\
\text { EPAs group } \\
\text { (n=137): IFC (3.85 } \\
\text { kHZ, 100-130Hz), } \\
\text { CUS (1.5W/2cm2) } \\
\text { for } 5 \text { minutes } \\
\text { and IR (1000nm, } \\
100 W, 50 \mathrm{~cm}) \text { for } \\
15 \text { minutes. }\end{array}$ & $\begin{array}{l}\text { VAS } \\
\text { ODI } \\
\text { FTF }\end{array}$ & $\begin{array}{l}\text { more significant } \\
\text { improvement in } \\
\text { pain levels and } \\
\text { spinal mobility in } \\
\text { the MDT group } \\
\text { compared to EPA }\end{array}$ & $\begin{array}{l}\text { - no double blin- } \\
\text { ding }\end{array}$ & $8 / 10$ \\
\hline
\end{tabular}

Legend: CUS, continuous ultrasound; EPAs, electrophysical agents; FTF, finger-to-floor test; GPE, Global Perceived Effect; IFC, interference currents; MCE, motor control exercises; MDT, Mechanical Diagnosis and Therapy; NPRS, Numeric Pain Rating Scale; ODI, Oswestry Disability Index; PSFS, Patient-Specific Functional Scale; RMDQ, Roland-Morris Disability Questionnaire; TSK, Tampa Scale for Kinesiophobia; USG, ultrasonography; VAS, Visual Analogue Scale. 
Ebadi et al. [12] conducted a RCT to compare the efficiency of TENS and diadynamic (Bernard) $\mathrm{cu}^{-}$ rrents (DDC) for direct pain relief in patients with LBP. Subjects meeting the following criteria were eligible for the experiment: age between 18 and 60 years, presence of chronic non-specific LBP of at least three months, and consent to participate in the experiment. The exclusion criteria included contraindications to electrotherapy, severe spinal trauma, previous spinal surgery, pain level of two or less (VAS) during the week before the study, use of analgesics less than 24 hours from the start of the study, and pregnancy. Thirty patients who met the above criteria were randomly assigned to one of two groups: TENS ( $\mathrm{n}=15,15$ minutes, $120 \mathrm{~Hz}$, pulse time: $100 \mathrm{~ms}$ ) and DDC (n $=15,10$ minutes of which 5 minutes for LP-longues periodes and 5 minutes for $\mathrm{CP}-$ courtes periodes). The level of pain was assessed using the VAS and an algometer to assess the pressure pain threshold (PPT) immediately before and after the therapy session and during quasi-follow-up assessments at 20 minutes and 48 hours after the procedures. An analysis of the study results showed a significant reduction in pain (VAS) only in the TENS group. The PPT levels increased significantly in both groups 20 minutes after the end of the study, but the effect did not persist until measurement at 48 hours.

In their RCT, Facci et al. [13] compared the efficacy of TENS and IFC in patients with LBP. The inclusion criteria were having chronic non-specific LBP located below the scapulae and above the gluteal cleft for at least three months and more than 18 years of age. Participants with significant degenerative changes in the spinal joints, who had undergone spinal surgery, with contraindications to electrotherapy, and with psychiatric illnesses and pregnant women were excluded from the study. The participants who met the above inclusion criteria were randomly assigned to one of three groups: IFC $(n=50)$, TENS $(n=50)$, and control $(n=50)$. In the IFC (base frequency: 4000 $\mathrm{Hz}$, modulated in the range of $20 \mathrm{~Hz}$ ) and TENS (20 Hz, pulse time: $330 \mathrm{~ms}$ ) groups, there were 10 therapy sessions, lasting 30 minutes each, which took place over 2 weeks; no treatment was carried out in the control group. All participants were assessed using the VAS, McGill Pain Questionnaire (MPQ), and RMDQ before and after the experiment. The study results showed a reduction in pain levels (VAS) in all groups, with an average of 4.50 in the IFC group, 3.92 in the TENS group, and 0.85 in the control group. The degree of disability (RMDQ) decreased by 6.59 points in the IFC group, by 7.20 points in the TENS group, and by 0.70 points in the control group. There was no statistically significant difference between TENS and IFC ( $p>0.05)$. A statistically significant difference was found between the IFC and TENS groups compared to the control group ( $\mathrm{p}<0.0001)$.

The prospective RCT by Bachmuller et al. [14] aimed to evaluate the effectiveness of TENS on functional improvement and pain relief in patients with LBP. Subjects over 18 years of age with chronic LBP of at least three months' duration, with or without radiculopathy, and with a pain intensity of at least 4 on the VAS were eligible for the study. Subjects with previous TENS treatment, spinal surgery, or contraindications to electrotherapy were excluded from the experiment. The subjects who met the criteria for participation in the study were randomly assigned to one of two groups: a TENS $(n=117)$ and a placebo group $(n=119)$. The applied therapy in the TENS group included conventional mode $(80-100 \mathrm{~Hz}$, pulse duration: 50-100 $\mu \mathrm{s})$ and acupuncture mode $(1-4 \mathrm{~Hz}$, pulse duration: $100-400 \mu \mathrm{s})$. The duration of a single treatment was 60 minutes, and the treatments were self-administered by the patients every day for 3 months using a CEFAR Primo Pro device. The treatment protocol was identical for the placebo group; however, the devices were modified not to generate current. On the day of the experiment, all participants were assessed using the RMDQ, the Dallas Pain Questionnaire (DPQ), the Short Form Health Survey (SF-36) for QOL, and the VAS. All participants were subjected to follow-up visits at 15 days, 6 weeks, and 3 months after the start of the study. The results showed 
no changes in functional level (RMDQ) between the groups during both follow-ups, at 6 weeks ( $\mathrm{p}$ $=0.351)$ and 3 months $(p=0.816)$. Significant improvement was noted only on the VAS between the first and last follow-up visits in the TENS group. There were no significant statistical differences in the other measured parameters (Table 2).

Table 2. Review of studies on the TENS method.

\begin{tabular}{|c|c|c|c|c|c|}
\hline Authors & Study protocol & Measures & Results & Limitations & PEDro score \\
\hline $\begin{array}{l}\text { Ebadi et al. } 2017 \\
{[11]}\end{array}$ & $\begin{array}{l}\text { TENS group } \\
(n=15): 15 \text { min. } \\
\text { - DDC group } \\
(n=15): 10 \text { min. }\end{array}$ & $\begin{array}{l}\text { VAS } \\
\text { PPT }\end{array}$ & $\begin{array}{l}\text { - reduction of pain } \\
\text { only in the TENS } \\
\text { group at } 20 \text { min } \\
\text { after the end of the } \\
\text { experiment } \\
\text { - the level of pain } \\
\text { sensitivity (PPT) } \\
\text { increased in both } \\
\text { groups at } 20 \\
\text { minutes post-test } \\
\text { (not significant in } \\
\text { further measure- } \\
\text { ments) }\end{array}$ & $\begin{array}{l}\text { - one specific sequ- } \\
\text { ence of DDC } \\
\text { - one therapeutic } \\
\text { session } \\
\text { - small study group }\end{array}$ & $9 / 10$ \\
\hline $\begin{array}{l}\text { Facci et al. } \\
2011[12]\end{array}$ & $\begin{array}{l}\text { group I: IFC } \\
(\mathrm{n}=50) \\
\text { - group II: TENS } \\
(\mathrm{n}=50): \text { in groups } \\
\text { I and II the the- } \\
\text { rapy consisted of } \\
10 \text { ses-sions of } 30 \\
\text { minutes each for } \\
\text { two weeks } \\
\text { - group III; control } \\
(\mathrm{n}=50)\end{array}$ & $\begin{array}{c}\text { VAS } \\
\text { MPQ } \\
\text { RMDQ }\end{array}$ & $\begin{array}{l}\text { - significant reduc- } \\
\text { tion in pain (VAS, } \\
\text { MPQ) and disa- } \\
\text { bility (RMDQ) in } \\
\text { groups I and II } \\
\text { - statistically insi- } \\
\text { gnificant differen- } \\
\text { ce between groups } \\
\text { I and II }\end{array}$ & $\begin{array}{l}\text { no blinding of } \\
\text { study partici- } \\
\text { pants and thera- } \\
\text { pists }\end{array}$ & $7 / 10$ \\
\hline $\begin{array}{l}\text { Bachmuller } \\
\text { et al. } 2011 \text { [13] }\end{array}$ & $\begin{array}{l}\text { TENS group } \\
\text { (n=117): conven- } \\
\text { tional and acu- } \\
\text { puncture TENS (1 } \\
\text { hour per day for } \\
\text { three months) } \\
\text { - placebo group } \\
\text { (n=119): no the- } \\
\text { rapy }\end{array}$ & $\begin{array}{c}\text { VAS } \\
\text { RDMQ } \\
\text { DPQ } \\
\text { SF-36 }\end{array}$ & $\begin{array}{l}\text { - no difference be- } \\
\text {-tween groups in } \\
\text { functional status at } \\
\text { three months after } \\
\text { therapy } \\
\text { - significant im-pro- } \\
\text { vement in pain } \\
\text { relief between the } \\
\text { 1st and last therapy } \\
\text { in the TENS group }\end{array}$ & $\begin{array}{l}\text { - no blinding of } \\
\text { therapists }\end{array}$ & $9 / 10$ \\
\hline
\end{tabular}

Legend: DDC, diadynamic current; DPQ, Dallas Pain Questionnaire; IFC, interference currents; MPQ, McGill pain questionnaire; PPT, pressure pain threshold; RMDQ, Roland-Morris Disability Questionnaire; SF-36, Short Form Health Survey for QOL; TENS, Transcutaneous Electrical Nerve Stimulation; VAS, Visual Analogue Scale. 


\section{PMEP method}

The aim of the RCT by Valenza et al. [15] was to examine the effectiveness of the PMEP on disability, pain levels, mobility, and stability of the lumbar spine in patients suffering from chronic non-specific LBP. The inclusion criteria were the presence of LBP without radiation to the lower limbs for at least three months, an age between 18 and 70 years, no contraindications to exercise, no symptoms of nerve root compression, and no previous or planned spinal surgery for the period of the study. A total of 54 patients who met the above criteria were randomly assigned to one of two groups: study $(n=27)$ and control $(n=27)$. The participants in the study group performed an exercise program based on the PMEP method twice a week for 45 minutes over 8 weeks. Treatments included mat exercises, ball exercises, stretching, and back muscle strengthening techniques. The control group only received a prophylaxis leaflet with instructions on how to adopt the correct posture, the need for an active lifestyle, and the principles of the technique of lifting weights from the floor. Before and after the experiment, all study participants were assessed using the VAS, RMDQ, and ODI. In addition, a modified Schober test (MST), FFT, and stability test of single-limb standing were administered. A comparison of the study results between the groups showed statistically significant differences in all measured parameters in favor of the PMEP group.

Cruz-Diaz et al. [16] conducted a RCT to investigate the efficacy of a 12-week PMEP on disability, pain, and kinesiophobia in patients suffering from LBP. The study enrolled 64 participants, aged 18 to 50 years, suffering from chronic non-specific LBP for at least 3 months without coexisting lumbago or other severe disease diagnoses (i.e., spinal tumors and fractures or severe spinal stenosis). The subjects were randomly assigned to one of two groups: study ( $\mathrm{n}=32$, PMEP) and control ( $\mathrm{n}=32$, leaflet). In the study group, the PMEP method was conducted twice a week for 50 minutes over 12 weeks by an experienced practitioner and included breathing exercises, mobilization of the limb and spine joints, and stretching and streng- thening exercises for the spinal muscles. A brochure on LBP was delivered to the participants in the control group. Before, after, and during the 6th week of the experiment, all the participants were evaluated using the RMDQ, VAS, and TSK. An analysis of the results after the study showed statistically significant differences in all measured parameters in favor of the study group ( $\mathrm{p}<$ 0.001). The most significant changes in disability (RMDQ) and kinesiophobia (TSK) were shown during week $6(\mathrm{p}<0.001)$, with no statistically significant difference during week $12(\mathrm{p}>0.05)$. The most significant decrease in pain level on the VAS was during week 6 , with a slight but statistically significant decrease during week $12(\mathrm{p}<0.001)$.

In their RCT study, Natour et al. [17] evaluated the efficacy of PMEP on QOL and pain levels in patients with LBP. Patients who met the following inclusion criteria were eligible for the experiment: chronic non-specific LBP for at least 12 months and located between the lower ribs and the gluteal cleft, with pain levels 4-7 on the VAS, and age between 18 and 50 years. Subjects with diagnosed lumbago, spinal tumors, significant spinal stenosis, spinal compressive fractures, fibromyalgia, previous spinal surgery, and body mass index $(\mathrm{BMI})>30$ were excluded from the study. A total of 60 patients who met the above criteria were randomly assigned to one of two groups: experimental $(\mathrm{n}=30)$ and control $(\mathrm{n}=$ 30). The participants in both groups were encouraged to use pain medication throughout the experiment if pain severity was above $8 / 10$ on the VAS. The treatment in the experimental group consisted of two PMEP sessions per week of 50 minutes each for 90 days. A physiotherapist with 10 years of experience conducted the PMEP. The control group received only pharmacotherapy. All study participants were evaluated using the SF-36, RMDQ, VAS, sit-and-reach test (SRT), and a questionnaire on the use of pain medications. Evaluations were performed before and after the experiment and after 45, 90, and 180 days as follow-ups. An analysis of the results showed a statistically significant difference in the reduction 
of pain sensation (VAS, $\mathrm{p}<0.001$ ), functional level (RMDQ, $\mathrm{p}<0.001$ ), QOL (SF-36, $\mathrm{p}<0.001$ ), and the consumption of analgesic medications at 45,90 , and 180 days after the study $(\mathrm{p}<0.01)$ in favor of the experimental group (Table 3 ).

Table 3. Review of studies on the PMEP method.

\begin{tabular}{|c|c|c|c|c|c|}
\hline Authors & Study protocol & Measures & Results & Limitations & PEDro score \\
\hline $\begin{array}{l}\text { Valenza et al. } \\
2016[14]\end{array}$ & $\begin{array}{l}\text { - PMEP group } \\
\text { (n=27): } 45 \text { min, } \\
\text { two times a week } \\
\text { per } 8 \text { weeks } \\
\text { - control group } \\
\text { (n=27): informa- } \\
\text { tion leaflet, no } \\
\text { therapy }\end{array}$ & $\begin{array}{c}\text { VAS } \\
\text { RDMQ } \\
\text { ODI } \\
\text { MST } \\
\text { FTF }\end{array}$ & $\begin{array}{l}\text { significant impro- } \\
\text { vement in favor of } \\
\text { the experimental } \\
\text { group in all measu- } \\
\text { red parameters }\end{array}$ & $\begin{array}{l}\text { - no follow-up } \\
\text { assessments }\end{array}$ & $8 / 10$ \\
\hline $\begin{array}{l}\text { Cruz-Diaz et al. } \\
2018 \text { [15] }\end{array}$ & $\begin{array}{l}\text { - PMEP group } \\
\text { (n=32): } 50 \text { min, } \\
\text { two times a week } \\
\text { per } 12 \text { weeks } \\
\text { control group } \\
\text { (n=32): informa- } \\
\text { tion leaflet, no } \\
\text { therapy }\end{array}$ & $\begin{array}{c}\text { VAS } \\
\text { RDMQ } \\
\text { TSK }\end{array}$ & $\begin{array}{l}\text { - significant impro- } \\
\text { vement in favor of } \\
\text { the experimental } \\
\text { group in all measu- } \\
\text { red parameters }\end{array}$ & $\begin{array}{l}\text { - no blinding of } \\
\text { study partici- } \\
\text { pants and thera- } \\
\text { pists } \\
\text { - } \text { small study group }\end{array}$ & $7 / 10$ \\
\hline $\begin{array}{l}\text { Natour et al. } \\
2014[16]\end{array}$ & $\begin{array}{l}\text { PMEP group } \\
\text { (n=30): } 50 \text { min, } \\
\text { two times a week } \\
\text { per } 180 \text { days }+ \\
\text { analgesic phar- } \\
\text { macotherapy } \\
\text { - control group: } \\
(\mathrm{n}=30) \text { : analgesic } \\
\text { pharmacothe- } \\
\text { rapy }\end{array}$ & $\begin{array}{c}\text { SF-36 } \\
\text { RMDQ } \\
\text { VAS } \\
\text { SRT } \\
\text { survey on } \\
\text { the use of } \\
\text { painkillers }\end{array}$ & $\begin{array}{l}\text { - significant im-pro- } \\
\text { vement in favor of } \\
\text { the ex-perimental } \\
\text { group in all measu- } \\
\text { red parameters }\end{array}$ & $\begin{array}{l}\text { - no blinding of } \\
\text { study partici- } \\
\text { pants and thera- } \\
\text { pists } \\
\text { - small study group }\end{array}$ & $8 / 10$ \\
\hline
\end{tabular}

Legend: FTF, finger-to-floor test; ODI, Oswestry Disability Index; PMEP, Pilates Method Exercise Program; RDMQ, Roland-Morris Disability Questionnaire; SF-36, Short Form Health Survey for QOL; MST, modified Schober Test; SRT, sit-and-reach test; TSK, Tampa Scale for Kinesiophobia; VAS, Visual Analogue Scale. 


\section{Summary}

All the studies presented in this paper are of good quality, as evidenced by the high assessment of the above papers by PEDro experts. The present review considered papers with a score of at least 7 on the PEDro scale. The average scores of the studies analyzed in this review according to the PEDro scale were: 7.7 points for the MDT method, 8.3 points for the TENS method, and 7.7 points for the PMEP method.

A review of studies on the MDT method showed an inconclusive evaluation of its effectiveness. In terms of reducing LBP, a slight improvement was indicated in two of the three papers cited. Only the study by Murtezani et al. [11] comparing the effectiveness of MDT with physical methods (TENS and DDC) showed a significant improvement in favor of the MDT method. Our review proved the beneficial effect of MDT on the pain-free range of motion of the lumbar spine and a reduction in the level of disability. The authors of the above studies agree on the need for further research to confirm the effectiveness of MDT in the treatment of LBP.

An analysis of the papers on the TENS method showed its effectiveness in reducing pain in all the studies cited. The level of disability (RMDQ) indicated the effectiveness of this therapy compared to the placebo but not compared to the IFC-treated group [13]. No significant differences in the measured parameters (i.e., pain, disability, and QOL) were observed between acupuncture and conventional TENS [14].

The authors of the papers evaluating the PMEP indicate its effectiveness in treating LBP, reducing the level of disability, and improving the mobility of the lumbar spine. In the cited studies, the PMEP method was compared with control groups in which no other forms of therapy were used except pharmacotherapy. Further studies comparing the effectiveness of the PMEP method with other physiotherapeutic methods are needed to demonstrate its positive effects on the parameters measured in the cited studies.

As mentioned above, the analyzed papers show that the TENS method, which is deemed to be the most popular and easy to apply, may significantly influence the functional status of patients suffering from chronic non-specific LBP. On the other hand, the MDT method requires much experience from therapists to apply it correctly, which may be reflected in the low effectiveness of its outcomes in the papers cited. Therefore, it seems necessary to conduct further RCTs on large study groups in which special attention is paid to the selection of experienced, certified MDT therapists to assess the effectiveness of this method as reliably as possible. It is also essential to research this method according to the guidelines of PEDro experts (i.e., to use double- and triple-blind trials and perform follow-up assessments). It seems equally important to compare different manual therapies and conduct high-quality meta-analyses and systematic reviews. However, clinical practice indicates that MDT is highly effective, especially in LBP management. The PMEP method proved to be the most beneficial, although, as noted earlier, further studies comparing its effectiveness with other methods are needed.

\section{Limitations of the study}

It should be noted that the present review has some potential limitations. The most important one seems to be the small number of included studies and the subjective selection of the physiotherapeutic methods. Extensive meta-analyses and systematic reviews by international scientific boards and societies, such as the Cochrane Collaborations, are needed to reliably assess the effectiveness of the methods analyzed. In particular, there is a lack of methodologically standardized RCTs on physiotherapeutic methods used in the treatment of LBP, such as using double and triple blinding, subjecting participants to follow-up assessments, and selecting therapists with similar professional experience. The studies analyzed in this review also present these limitations, which may lead to the inconclusive evaluation of their effectiveness. 


\section{Abbreviations}

BMI, body mass index (BMI); CP, courtes periodes; CUS, continuous ultrasound; DDC, diadynamic currents; EPAs, electrophysical agents; FFT, finger-to-floor test; GPE, general perception of therapeutic effect; GPE, Global Perceived Effect tool; IFC, interference currents; IR, infrared radiation; LBP, lower back pain; LP, longues periodes; MCE, motor control exercises; MDT, McKenzie Method of Mechanical Diagnosis and Therapy; MPQ, McGill pain questionnaire; MST, modified Schober test; NPRS, Numeric Pain Rating Scale; ODI, Oswestry Disability Index; PMEP, Pilates Method Exercise Program; PPT, pressure pain threshold; PSFS, Patient-Specific Functional Scale; QOL, quality of life; RCT, randomized controlled trial; RDMQ, Roland-Morris Disability Questionnaire; TENS, Transcutaneous Electrical Nerve Stimulation; TPK, Tampa Scale for Kinesiophobia; VAS, Visual Analogue Scale. 


\section{References}

1. Hoy D, Bain C, Williams G, et al. A systematic review of the global prevalence of low back pain. Arthritis Rheum. 2012; 64: 2028-2037.

2. Kamper S.J. et al. Musculoskeletal pain in children and adolescents. Braz J Phys Ther. 2016; 16: 10.

3. Global Burden of Disease, Injury Incidence, Prevalence Collaborators. Global, regional, and national incidence, prevalence, and years lived with disability for 310 diseases and injuries, 1990-2015: a systematic analysis for the Global Burden of Disease Study 2015. Lancet 2016; 388: 1545-1602.

4. Hartvigsen J. et al. What low back pain is and why we need to pay attention. Lancet 2018; 391: 23562367.

5. Balagué F. et al. Non-specific low back pain. Lancet 2012; 379: 482-491.

6. Hoy D. i wsp. The Epidemiology of low back pain. Best Pract Res: Clin Rheumatol. 2010; 24: 769-781.

7. Głowny Urząd Statystyczny. (2016) Stan Zdrowia Ludności Polski w 2014 r. Dostęp: https://stat.gov. pl/obszary-tematyczne/zdrowie/zdrowie/stan-zdrowia-ludnosci-polski-w-2014-r-,6,6.html.

8. Garcia A.N. et al. McKenzie Method of Mechanical Diagnosis and Therapy was slightly more effective than placebo for pain, but not for disability, in patients with chronic non-specific low back pain: a randomised placebo controlled trial with short and longer term follow-up. Br J Sports Med. 2018: 52 (9): 594-600.

9. Halliday M.H. et al. A Randomized Controlled Trial Comparing the McKenzie Method to Motor Control Exercises in People With Chronic Low Back Pain and a Directional Preference. J Orthop Sports Phys Ther. 2016; 46 (7): 514-522.
10. Hodges P.W., van Dieën J.H., Cholewicki J. Time to Reflect on the Role of Motor Control in Low Back Pain. J Orthop Sports Phys Ther. 2019; 49 (6): 367369.

11. Murtezani A. et al. A comparison of mckenzie therapy with electrophysical agents for the treatment of work-related low back pain: A randomized controlled trial. J Back Musculoskelet Rehabil. 2015; 28 (2): 247-253.

12. Ebadi S. et al. No immediate analgesic effect of diadynamic current in patients with non-specific low back pain in comparison to TENS. J Bodyw Mov Ther. 2018; 22 (3): 693-699.

13. Facci L.M. et al. Effects of transcutaneous electrical nerve stimulation (TENS) and interferential currents (IFC) in patients with non-specific chronic low back pain: randomized clinical trial. Sao Paulo Med J. 2011; 129 (4): 206-216.

14. Buchmuller A. et al. Value of TENS for relief of chronic low back pain with or without radicular pain. Eur J Pain 2012; 16: 656-665.

15. Valenza M.C. et al. Results of a Pilates exercise program in patients with chronic non-specific low back pain: a randomized controlled trial. Clin Rehabil. 2017; 31 (6): 753-760.

16. Cruz-Díaz D. et al. The effectiveness of 12 weeks of Pilates intervention on disability, pain and kinesiophobia in patients with chronic low back pain: a randomized controlled trial. Clin. Rehabil. 2018; 32 (9): 1249-1257.

17. Natour J. et al. Pilates improves pain, function and quality of life in patients with chronic low back pain: a randomized controlled trial. Clin Rehabil. 2015; 29 (1): 59-68. 